\title{
Suitability and Contribution of Agile Methods in Mobile Software Development
}

\author{
Asra Khalid \\ Department of Software Engineering, University of Engineering \& Technology, Taxila, Pakistan \\ Email: asra_05@yahoo.com \\ Sobia Zahra \\ Department of Software Engineering, University of Engineering \& Technology, Taxila, Pakistan \\ Email: zahra.sobia@gmail.com \\ Muhammad Fahad Khan \\ Department of Software Engineering, University of Engineering \& Technology, Taxila, Pakistan \\ Email: fahad.khan@uettaxila.edu.pk
}

\begin{abstract}
Boom of mobile app market is phenomenal and so are the challenges for developing these mobile applications. With changing mobile market technology and trends, various technical constraints for building these mobile apps also cropped up with time. Tradition development approaches are unable to tackle these challenges and technical limitations of mobile market. Analyzing this situation researchers have proposed numerous agile practices to develop people oriented mobile app which embrace their changing needs. This paper provides a brief overview of some effective and commonly used agile approaches that adds value to mobile software business. Suitability of these approaches to fit mobile needs is also discussed in this paper. It is suggested that agile innovations offer a solution for mobile applications and examine developer who are in quest of building high quality products.
\end{abstract}

Index Terms-Agile Methodology, Mobile app Development, Mobile-D, RaPiD7, MASAM, SleSS.

\section{INTRODUCTION}

Rate of introduction of new kind of mobile phones in market is quite higher than the rate of advancement in techniques for developing applications for these mobile phones. Most of mobiles that are common in market are those smart phones that have very high computation power. But these smart phones required specialized applications due to internal characteristics of mobile phones which make requirements for applications quite specified [1]. Mobile app market is expanding exponentially. Gartner studies forecast that over 185 billion applications will have been downloaded from mobile app stores by the end of 2014, since the first one was launched in July 2008[2]. Another Gartner study [2] exemplifies that 428 million mobile devices were sold worldwide in 2011 Q1, a $19 \%$ increase from the previous year.
These statistical study shows that mobile phone is a fundamental necessity of our lives. Nowadays almost everyone owes his/her personal phone not only for messaging and calling purpose but also for entertainment, communication over the web, complex business transaction, instant accessibility of required information and much more.

Mobile computing is everywhere. It is enabling insurance, trading, banking, retail in B2C, empowering field employees, improving supply chain and business information in B2E and B2B. While in M2M it facilitates exchange of information between machines and businesses. But for developing all these types of mobile apps, development teams are facing numerous challenges like increasing mobile app complexity, changing hardware, multiple platforms, security, network communication, easy to use UI, managing requirement from multiple stakeholders and managing activities from entire development lifecycle.

Mobile platforms support network resources usage in mobile phones extensively so it made mobiles a good choice as compared to personal computers and their software. Software which is developed for mobile applications have their own characteristics and constraints which are applied to almost all lifecycle stages. For mobile application, software development process is quite different from traditional methodologies [3]. Most important features which made mobile applications different from traditional applications are identified. These include a large number of competitors, difficult to find requirements, and time constriction on delivery of developed software. Mobile application developer also face changing environment in which customer requirements change frequently [4]. Technical limitations in mobile applications development are limited physical resources, frequently changing requirement, a large number of different devices having different operating system and their own hardware specifications [5]. Other limitations in mobile devices are security, bandwidth, screen size, memory capacity, 
operational power, small keyboard size, coverage, limited battery time and different input methods. Some of these are inherent characteristics of mobile device and others are due to change in technology. These inherent constraints should be resolved in mobile application development [6]. Mobile application developers has to keep cost of developing process of mobile application less and they also strike for developing the application which has attributes which make it internally efficient [7].

Talking about software development history agile application development is newer in it. Traditionally water fall and other extension of it were used for software development. Agile methodology is based on principles of Lean Methodology and agile methodology for manufacturing, whose bases were on idea of adaptability of enterprise to a changing development environment. Agile methodology has unique features like in agile methodology individuals and their interactions are more valuable than tools and techniques used, software to develop is important than all the documentation of its development process, changes are welcomed than to strictly following defined requirement based on signed contract, and collaborating with end user is given preference on talking about contract terms [8].

When some technique is introduced it receives both negative and positive comments same is the case for agile development methodology. Most important view against agile is no defined validation method for activities and practices used in agile methodology. Another issue is that it is difficult to integrate other old practices with agile practices but it is possible that developer may want to use mix of these methodologies. Mix of both methodologies is used in some projects and a balance is achieved between these methodologies [9]. It is also difficult to find difference between agile and ad-hoc programming techniques mainly agile methods provide a structured development technique but ad-hoc programing do not follow any proper development method or approach [10].

On the positive side usage of agile development method made development of good quality software in less time. Agile methodologies improved pervious methodologies as it encourage change in requirement during development process. So while developing through agile it is not required to follow the rule of freeze requirements on the other hand requirement changes during development process [11]. There are many approaches in agile methodology these all approaches share some characteristics which are prototyping, iterative development, and less documentation more coding [12].

Literatures review covers the comparison of agile methodologies on the basis of limitations and characteristics for mobile application development. Agile methodology has no defined boundaries which cause difficulty in comparison process. Mostly these comparative studies are done by defining four categories which are as follows: social influences and human, bases of agile methodology, introduction and adaptation, and finally comparative study. In these comparative studies it is found that usage of agile methodology is beneficial if it is used with traditional methodologies [13]. Literature review is covered in Section II. Section III briefly explains changing mobile environment. Some of the commonly used agile practices for development of mobile apps are reviewed in Section IV. Some of Agile Home ground characteristics are mapped to mobile development in Section V. Section VI points out some salient benefits of using agile methodology. The conclusion of this documentation is presented in Section VII.

\section{LITERATURE REVIEW}

Agile is emerging Software engineering methodology based on people and embracing their changing needs. It is an iterative and incremental approach of developing software applications through proper planning and management of self organizing - cross functional teams. Agile is iterative, emergent and flexible approach where project lifecycle is guided by product features. It is a good approach for flexible and turbulent environment. There is high level of communication and coordination between the developing team and main focus is whether customer requirements are fulfilled or not. There are some specific agile approaches like extreme programming, scrum, lean development, feature driven development and dynamic system development methods and scrum [14] which come under the umbrella of agile development.

Robert holler mentioned in his paper that to develop successful mobile applications a lot of problems are faced by development teams that are - introduction of new standards, changing platforms, discontinuous connections, various devices, and changing user-interface and input technology. A lot of potential users with demand of fast delivery of these applications are also a reason of risks. Mobile application developer should develop applications which are efficient so that these applications are less costly and high in quality. As life of mobile applications are short so their development time also. Due to rapid delivery requirement of mobile application users many approaches associated with traditional application development cannot be applied in mobile application development. Mostly mobile application developer cannot spend $60 \%$ or more of their development time and efforts on task which are not associated with development of running applications. And due to change in requirement and technology they cannot wait till the end of development cycle to start testing of applications. As they have to develop an efficient application with in less time period with high quality and which can satisfy user needs. To achieve these goals many developers has started using iterative and incremental delivery techniques to cope with the problems of constant change in requirement of users and development methods. In case when technical environment and business strategies are changing agile software development offers many opportunities to developer. It not only help in user involvement in development process but also allow developer to deliver a high quality product in few weeks 
which ensure team ability to deliver predictably, deploy end product with more confidence and can change product more easily if any change occur in requirement. Agile development techniques help team to deliver the highest business value rapidly, with minimum technical risks [7].

Jeffrey found that with the new technologies in world and advancement of internet has changed the rules for software development processes. Nowadays business demand for short development cycle of product and due to new technologies introduction requirements of user change even in development processes, due to these reason it is almost impossible to develop software by following traditional development methods as they don't allow for change in requirement and rapid development of software. To manage change in requirement and to rapidly developing product software developers have developed agile software development methodologies in which iterative development, templates, different prototyping techniques and less documentation is used. In this paper through a research project agile software development methods were investigated for this online survey was used which was sent to software development expert worldwide. Data collected through this survey was used to identify factors that affect agile methodologies. Through this survey the factors found that impact agile software development methods are training, management methodology, usage of resources outside of organization, and corporation size. Other factors like models, implementation planning, development team at same place, software and tools used for development for internet or intranet which is considered important in agile development methodology has not much impact on agile methodology. In the end of this paper it was discussed that most of the factors that are found in this survey are controllable through management. So for the development companies or organizations which want to use agile software development methodology can tackle many of significant factors that affect agile methodology through proper management and can increase chances of successful development of quality software products through their methodology [15].

Vahid Rahimian in his paper quotes that with the advancement of networking and mobile computer technology many new techniques and limitations are created in field of software development technology. Due to advancement of mobile phones and introduction of operating system in them made usage of mobile phones very vast. Many applications are started to develop for mobiles which were only developed for PCs before. Applications which are developed for mobile phones have their own unique constraints and requirements. These constraints include mobile screen size, battery timings, memory limitation and small life time of applications. All these constraints significantly impact traditional development methodologies that are used for application development for PCs. Due to these reasons traditional methodologies required improvement so that they can be used for mobile application fulfilling their own constraints and conditions. In this paper all the possible challenges for mobile application development are examined. For this reason internal characteristics of mobile operating system are studied and it is identified that what kind of application are currently developed. Quality requirement for that application is also observed. All the characteristic which are identified and all the requirement found for application development for mobile application showed that agile methodologies are far better for mobile application development than any other traditional method. In this paper all the requirement which are specific to mobile application are discovered and by using these requirement a new methodology is proposed which is based on agile software development methodologies. For this hybrid methodology design approach is used. It is claimed that this methodology can be used for development of mobile applications [2].

Juhani Warsta found that due to change in current software requirement and demand of rapid development of software has forced many organizations to change their development methodology from traditional. Many organizations have changed their strategy or are considering changing it with more agile methodologies. In this paper it is tried to make sense out of jungle of agile software methodologies. The results of this paper can be used by development experts to understand properties of each methodology so that they can decide when to use which methodology. Comparative analysis was used for this purpose. This analysis is done on base of five perspectives which are software development life cycle with the process aspect, theoretical principles vs. concrete regulation, project management, generally predefined vs. situation suitable, and empirical evidence. It is claimed in this paper that most of method cover most phases of life cycle. But most of method doesn't provide any management support, and mostly theoretical principles are more used in these methods. In literature general solutions have a strong support and empirical evidence is very narrow. By observing all these new direction for agile methodology are proposed. Most of agile method doesn't clarify their range of applicability they should clarify it. Method specialization should be focused rather than general methodologies more over this specialization should help in increasing conceptual synchronization. Agile method should support management so that development can be done in more managed way. It is also suggested in this paper that instead of introducing new methods problems in existing agile methodologies should be addressed [16].

Luis Corral, Alberto Sillitti, Giancarlo Succi[17] focused on the issue of developing mission critical mobile application. They say that there is no framework for the mobile applications to be developed according to the quality standards necessary for mission critical systems. Though there are some standards (e.g. CMMi, ISO 12207, and ISO 15504) that are followed in software developments, yet they are general enough to incorporate mobile application development as well. And some models (e.g. Mobile-D or RaPiD7) for mobile application development are also used, which exploit agile processes and practices to embrace changing application needs, but 
they are not developed for mission critical system [17]. Mobile-D and RaPiD7 both are based on agile practices and their main focus is on reduction of development cycle so they might fail to assure the security, safety and performance needed by mobile application to get certification from competent authorities. They concluded that first of all agile practices should be used for mobile application development but these methodologies based on agile model need to be fine-tuned to meet the needs of mission critical applications. They recommended finding the suitability of processes, products and documentation for mission-critical system and developing applications to be deployed in environments with no failure modes.

Harleen K. Flora, Dr. Swati V. Chande[18] have reviewed and analyzed mobile application development processes using agile methodology. According to them agile practices are natural fit for mobile application development. Starting from Mobile-D, they covered all other agile practices for mobile app development, like RaPiD7, Hybrid Methodologies, MASAM and SLeSS.

\section{CHANGING MOBILE ENVIRONMENT}

Mobile environment is turbulent with respect to customer demands and market strategies. Rather backgrounds of this chaotic environment are ever changing mobile hardware, different models of mobile phone and variant software platforms which run on these mobile phones. Therefore an application needs to be cross platform and support interoperability. Developers face plenty of challenges and technical limitations while developing apps for multiple platforms and various devices, as well as constantly changing requirements of mobile market. So they need processes that respond efficiently while facing these challenges and cope with changing requirements of mobile environment. Consequently, these processes should facilitate in generation of high quality products. Agile Methods, spiral methodology, NPD engineering and Plan base methodologies [19] have been proposed to cope the needs of mobile app development and to provide high quality products.

\section{AGILE FOR MOBILE DEVELOPMENT}

The focus of agile approach is to deliver iterative and increment product; one can build a product with continuous planning, adaptation and modification consequently delivers the product much efficiently to the customer. Afterwards literature study reveals that agile is considered as best fit for mobile app development [19, 20].

Many mobile app development processes based on agile practices were proposed by different researcher. This journey started from Mobile-D and is yet in progress.

Abrahamsson et al. proposed one of the fundamental approaches for mobile app development - Mobile-D [20]. This approach is drawn from agile practices and can meet the needs of changing mobile environment. Architecture
Line, an architectural concept, was introduced to produce framework for future mobile app development. It works on 9 principle elements extracted from agile practices and is tested on some development project and effectively evaluated against CMMI level 2. Mobile-D is good for small teams and short projects.

Afterwards, Dooms et al. proposed a method to produce better product based on improved documentation, known as RaPiD7 (rapid production of documentation, 7 steps) [19]. It was developed within Nokia in the 20022003 timeframe. The idea was simple - to create reality based document with as minimum effort as possible. We know that by better human interaction and documentation better quality product can be developed. So, workshops are conducted to facilitate documentation and plan human interaction for the project. RaPiD7 actually, embraces two very agile practices: Whole Team \& Do the Simplest Thing That Will Work.

Another mobile development methodology is Hybrid methodology Design [20] which is based on many practices like agility, review meeting, reusability support, market awareness, market base architecture, etc. this methodology is completed in four iterations, development starts with generic SDLC, firstly agile practices are incorporated into it. In second iteration market analysis is done and activities from New Product Development are integrated to gain competitive advantage. Adaptive software development ideas are included in third phase and to reduce the level of risk in the product fourth iteration adds prototyping to the project development life cycle. But this methodology is high level and no case studies or test result can be found from literature studies.

MASAM (mobile application software agile methodology) [20] was proposed by Jeong et al. is based on swift production and delivery of mobile applications using Extreme Programming, Agile unified Process, RUP and SPEM. It has some variation, from Mobile-D rather shows strong tie with it - like follow up tools and project management. It has three process assets i.e. roles, tasks and work product. It undergoes four phases namely Preparation, Embodiment, Development and Commercialization Phase. Though we can't find any real world implementation of MASAM but researchers suggest it to be followed in small companies.

Later on, Cunha et al. integrated Scrum with Lean Six Sigma and proposed SLeSS [20]. Scrum is used for software development and project management even for complex projects while Lean Six Sigma (LSS) reducing defects and eliminating waste provide better quality product. It provides continuous process improvements. So SLeSS help in handling requirement evolution throughout project lifecycle. SLeSS believes in incremental development, firstly scrum is implemented and when it is well establish in any organization then LSS is implemented as quality framework.

Some common agile based mobile application development practices are analyzed, now it's up to developer and organization which methodology they select based on team size and project complexity. 


\section{AGILE METHODS AND EVOLVING MOBILE MARKET}

Boehm anticipated home ground for agile development [20]. An organization can be called agile home ground if it is flexible enough to embrace changing needs, development team with less than 10 members and all members are hard working and capable of facing challenging environment, risk identification at earlier stages and these risk causes discomfort between team members and requirement are changing more than $50 \%$ during development lifecycle.

Table I provides mapping of agile home ground characteristics to corresponding view of mobile app development [20], made available in 2005. Though agile methods were considered best fit for mobile software but the fact is that mobile devices and platforms are evolving at very fast speed, and at that time mobile business was different from current one.

Table 1. Mapping of Agile home ground themes and Mobile App Development [21]

\begin{tabular}{|c|c|}
\hline $\begin{array}{c}\text { Ideal Agile } \\
\text { Characteristic }\end{array}$ & Mobile App Development \\
\hline $\begin{array}{l}\text { High } \\
\text { environment } \\
\text { volatility }\end{array}$ & $\begin{array}{c}\text { Dynamic Environment- innovation } \\
\text { in mobile phone devices is growing } \\
\text { per year }\end{array}$ \\
\hline $\begin{array}{l}\text { Identifiable } \\
\text { customer }\end{array}$ & $\begin{array}{l}\text { Number of users are unlimited and } \\
\text { increasing exponentially }\end{array}$ \\
\hline $\begin{array}{l}\text { Small } \\
\text { development } \\
\text { teams }\end{array}$ & $\begin{array}{l}\text { Mostly mobile apps are developed } \\
\text { by small SME companies }\end{array}$ \\
\hline $\begin{array}{l}\text { Object-oriented } \\
\text { development }\end{array}$ & Mostly C++ or Java is used \\
\hline $\begin{array}{l}\text { Non-safety } \\
\text { critical software }\end{array}$ & $\begin{array}{l}\text { Generally mobile software are used } \\
\text { for entertainment purpose as mobile } \\
\text { terminals are not reliable }\end{array}$ \\
\hline $\begin{array}{c}\text { Application } \\
\text { level software }\end{array}$ & Mainly Stand-alone applications \\
\hline Small Systems & $\begin{array}{l}\text { Variable size but mostly mobile } \\
\text { apps are less than } 10,000 \text { lines of } \\
\text { code }\end{array}$ \\
\hline $\begin{array}{c}\text { Short } \\
\text { development } \\
\text { cycles }\end{array}$ & $\begin{array}{l}\text { Mobile applications and services } \\
\text { can be developed in 1-6 months. }\end{array}$ \\
\hline
\end{tabular}

Almost after a decade mobile domain has made significant advancements. So this mapping is somewhat controversial and up to date discussions needs to be incorporated to update this mapping. Differences between this mapping and current status of mobile domain are identified as under [19].

- Though new models, new devices and platform are introduced each year but still mobile developers also have settles operating platform like iOS and Android and they possess their own APIs and SDKs. So new models can easily interact with previous one.
- Micro companies are more interested in mobile software development but we can't neglect the fact that nowadays large corporate organizations also show interest in developing mobile apps.

- The era has gone when mobile apps were just used for entertainment purpose. Now user needs are different so there are mobile apps for banking as well as health monitoring and these apps need to follow strict standards. Consequently we can't classify them as non-critical software.

- Nowadays mobile apps are no more standalone. They interact with other system as well as collaboration tool using hardware resources, etc. this implies that mobile software is not anymore small.

With the advancement of mobile domain, development practices also keep on evolving throughout this era. Certain common agile practices of today are discussed earlier on. These practices cope with today's turbulent mobile environment. One of these approaches is SLeSS [20] which mitigates several shortfalls of agile methods by applying continuous process improvement with the help of quality control framework. It merges two different perspectives - initially implements scrum (light weight development practices) and then implements LSS (Lean Six Sigma) which is a heavy quality control methodology.

Methodologies for mobile software development are still being introduced as it is a continuous process, so there is no hard or fast rule to choose some methodology among all of these. Rather one should go through pros and cons of using these methodologies while developing some specific app, and then pick the one with maximum advantages.

\section{BENEFITS OF USING AGILE}

Besides the fact that agile provides significant ways to speed up the development of mobile app projects, there are some other benefits as well - that count in enhancing the market position of your organization [22].

\section{A. Boost up delivery}

Idea behind agile approach is the same - build minimum viable product and deliver it to your customer in minimum possible time. So the first delivery reaches the customer with prioritize feature in very short duration of time and this makes the customer happier. In mobile apps the charm of applications lies in curiosity that there are some features yet to come. This fast delivery of product and inquisitiveness of versioning factor marks up market value of that product [22].

\section{B. Responsiveness towards changing market needs}

Technology is enhancing and changing with very fast pace and so is the proliferation in mobile market [22]. People interests and needs keep on changing with the change in surrounding environment. Thus, need of the hour is to cope with changing market trends and customers requirements efficiently. To bloom in mobile market an organization needs to deliver as fast as possible. 
And this is what Agile is all about- people oriented and embrace changing needs. So by implementing agile approaches an organization can gain profit as well as customer loyalty.

\section{Risk identified at early stage}

Agile is an adaptive approach in which the team tackles the problems as they arise. Though we can't foresee all the problems at the very start of the project but still the state of the art is that the team must be well prepared to undertake any risk coming on their way. Risks are identified at earlier stages because of customer involvement and feedback at each phase of the project [22]. In traditional development approaches it may happen that a team realizes just before the final release, that there is some major flaw in the product. So agile add value to the business by overcoming all the risk that may encounter during product development.

\section{CONCLUSIONS}

Needs and trends of mobile market are ever changing, so it is difficult for the developer to provide quality product within deadline. Keeping in view these changing needs and novelty of mobile hardware, agile methodology is recognized as best practice for mobile app development. Different approaches, based on agile manifesto have been proposed. This scientific documentation provides a review of available agile approaches for mobile app development. It depends on developer which approach he adheres, depending upon project complexity and size of team. Some of the benefits of using agile practices are also highlighted in this paper.

\section{REFERENCES}

[1] "Collaborative and agile development of mobile applications" Ayushman Jain http://www.slideshare.net/aupsy/mobile-webcast.

[2] Rahimian, V.; Ramsin, R., "Designing an agile methodology for mobile software development:A hybrid method engineering approach," Research Challenges in Information Science, 2008. RCIS 2008. Second International Conference on , vol., no., pp.337,342, 3-6 June 2008.

[3] Andrei Cristian Spataru, "Agile Development Methods for Mobile Applications" http://citeseerx.ist.psu.edu/viewdoc/download?doi=10.1.1. $186.1292 \&$ rep=rep1\&type=pdf, 2010.

[4] Abrahamsson, P., Hanhineva, A., Hulkko, H., Ihme, T., Jälinoja, J., Korkala, M., “ Mobile-D: an agile approach for mobile application development. Conference on Object Oriented Programming Systems Languages and Application" Companion to the 19th annual ACM SIGPLAN conference on Object-oriented programming systems, languages, and applications (pp. 174-175). Vancouver: ACM.

[5] Abrahamsson, P., "Agile Software Development of Mobile Information Systems. In Advanced Information Systems (pp. 1-4). Berlin: Springer".

[6] Hayes, I. S., "Just enough wireless computing. Prentice Hall".
[7] Robert Holler President \& CEO, VersionOne "Mobile Application Development: A Natural Fit with Agile Methodologies".

[8] http://www.versionone.com/pdf/mobiledevelopment.pdf , 2006.

[9] Agile Alliance, "Agile Software Development Manifesto. Retrieved from Manifesto for Agile Software Development" http://agilemanifesto.org/.

[10] Boehm, B., "Get Ready for Agile Methods, with Care. Computer http://ieeexplore.ieee.org/stamp/stamp.jsp?tp=\&arnumber= 976920\&userType=inst, 2002.

[11] Salo, O., "Enabling Software Process Improvement in Agile Software Development Teams and Organisations. Helsinki:

VTT" http://www.vtt.fi/inf/pdf/publications/2006/P618.pdf.

[12] Lindstrom, L. \& Jeffries,R. "Extreme programming and agile software development methodologies. Information Systems Management. 21(13), 41-53".

[13] Holmstrom, H., Fitzgerald, B., Agerfalk, P., \& Conchuir, E., "Agile practices reduce distance in global software development. Information Systems Development. 23(3)".

[14] Dyba, T., \& Dingsoyr, T., "What Do We Know about Agile Software Development? IEEE Software , 26, 6-9".

[15] Kaushal Pathak, Anju Saha "Review of Agile Software Development Methodologies".

[16] Jeffrey A. Livermore, "Factors that Significantly Impact the Implementation of an Agile Software Development Methodology".

[17] Juhani Warsta, Mikko T. Siponen and Jussi Ronkainen, "New Directions on Agile Methods: A Comparative Analysis Pekka Abrahamsson".

[18] Luis Corral, Alberto Sillitti, Giancarlo Succi "Preparing Mobile Software Development Processes to Meet MissionCritical Requirements".

[19] Harleen K. Flora, Dr. Swati V. Chande "A review and anaysis on mobile application development processes using agile methodlogies".

[20] Luis Corral, Alberto Sillitti, Giancarlo Succi "Software Development Processes for Mobile Systems, Is Agile Really Taking Over the Business?".

[21] Harleen K. Flora, Dr. Swati V. Chande "A review and anaysis on mobile application development processes using agile methodlogies".

[22] Pekka Abrahamsson, "Keynote: Mobile software development - the business opportunity of today".

[23] Anne-Marina Dicksonn, Why an Agile approach is best for mobile development http://digitalministry.com/AU/articles/1897/Why+an+Agil e+approach+is+best+for+mobile+development/1.

Engr. Asra Khalid is a MS Scholar as well as Research Associate in the Department of Software Engineering at University of Engineering and Technology Taxila, Pakistan. She graduated from University of Engineering and Technology Taxila in Software Engineering in July 2012. Her areas of interest are Mobile Application Development, Computer Graphics, Desktop Application Development, Object Oriented programming, Software Design \& Architecture.

Engr. Sobia Zahra completed her BS Software Engineering degree in July 2012 from University of Engineering and Technology Taxila, Pakistan. Her areas of interest are Mobile Application Development, Web Development, Data mining, 
Software Quality Assurance, Software Requirement Engineering and Operating System.

Currently she is MS Scholar as well as Research Associate in the Department of Software Engineering at University of Engineering and Technology, Taxila, Pakistan.

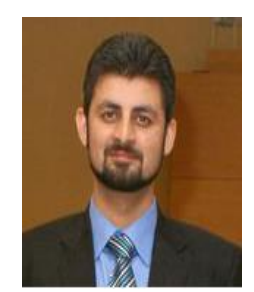

Engr. Muhammad Fahad Khan did his Bachelors in Software Engineering and MS in Computer Engineering from University of Engineering and Technology Taxila, Pakistan in 2007 and 2010 respectively.

Currently he is enrolled in $\mathrm{PhD}$ and also serving as an Assistant Professor in the Software Engineering department of University Of Engineering and Technology Taxila, Pakistan.
His areas of interest are Internet Application development, Object Oriented Programming, Software Design and Architecture, Discrete Structures, Computer Communication and Networks.

How to cite this paper: Asra Khalid, Sobia Zahra, Muhammad Fahad Khan,"Suitability and Contribution of Agile Methods in Mobile Software Development", IJMECS, vol.6, no.2, pp.56-62, 2014.DOI: 10.5815/ijmecs.2014.02.08 